DOI: $10.14451 / 1.192 .150$

\title{
СОВРЕМЕННЫЕ НАПРАВЛЕНИЯ ИННОВАЦИОННОГО РАЗВИТИЯ РЕГИОНА
}

\author{
(c) 2020 Огнивцев Сергей Борисович \\ доктор экономических наук, профессор
}

заместитель директора ОКУ «Агентство по инновациям и развитию социальных и экономических проектов», директор Института системного анализа и интеллектуальной собственности

В настоящее время можно констатировать, что надежды на переход нашей страны и её регионов на инновационный тип развития не оправдались. В связи с этим представляется весьма актуальным пересмотр целей, задач, направлений и мер поддержки развития инноваций на региональном уровне. В этой статье анализируются возникшие вызовы и выявленные проблемы инновационного развития. На этой основе с учетом сформулированных президентом страны национальных целей и национальных проектов предложены новые цели и направления регионального инновационного роста. Среди них главенствующую роль играют стимулирование инновационной активности крупных и средних предприятий региона, освоение апробированных зарубежных и доказавших свою эффективность отечественных инноваций, поиск новой смарт-специализации региона. Предложены критерии оценки эффективности новых направлений инновационного развития.

Ключевые слова: национальные цели, инновационное развитие, смарт-специализация, инновационная активность, институциональное и организационное обеспечение, цифровизация.

\section{Введение}

Предположение о том, что национальная и региональная инновационные системы будут постоянно генерировать разнообразные инновации, которые будут самопроизвольно продвигаться в бизнес, оказалось несостоятельным. Риски освоения инноваций оказались не приемлемы для большей части предприятий [1]. С аналогичной проблемой столкнулись даже наиболее развитые и казавшиеся совершенными инновационные системы. Так, в 2014 году столкнувшиеся с указанной проблемой США создали Национальную сеть инноваций в составе 14 институтов-консорциумов со значительным государственным участием [2], деятельность которых направлена на внедрение инноваций в различные отрасли экономики.

В настоящее время Россия, в целом, и ее регионы, в частности, столкнулись с рядом вызовов:

1. Изменение мировых трендов развития от глобализации к национальной экономической изоляции и стремлению к автаркии. Brexit и политика администрации США стали ярким проявлением новой тенденции ориентации сугубо на национальные интересы, возрождение национальной промышленности и защиту собственных рынков путем введения тарифных и нетарифных ограничений. Ослабление глобализации и ограничения в торговле высокотехноло- гичной продукцией негативно сказываются на инновационном развитии.

2. Обострение торговых войн. Современный этап экономической эволюции характеризуется возникновением и развитием множества торговых войн между различными странами и на многих рынках. Наиболее впечатляющим примером торговой войны является столкновение экономических интересов США и Китая [3]. Торговая война на рынке нефти привела в 2020 году к резкому падению цен и резкому ослаблению рубля. Это негативное явление для инвестиционных и инновационных процессов.

3. Санкционное давление на Россию. США, ЕС и некоторые другие страны ввели против России большие пакеты санкций. Россия была вынуждена принять ряд контрсанкций к этим странам. Санкции оказали неоднозначное влияние на различные отрасли. Так, для сферы АПК они были благотворны и стимулировали рост производства. На инновационную сферу санкции оказывают негативное воздействие.

4. Усиление международной конкуренции в сфере инноваций. Переход развитых стран к шестому технологическому укладу, ядро которого составляют NBIC-технологии (нано-, био-, информационные и когнитивные технологии), создает высокие конкурентные риски для России, в экономике которой, по экспертным оценкам [4], преобладают пока четвертый (50\%) и третий 
(30\%) уклады, а пятый уклад занимает только $10 \%$.

Проблемы, цели и задачи инновационного развития региона

Развитию инноваций препятствует ряд проблем, часть которых является общероссийскими.

1. Слабый валютный курс по отношению $\mathrm{k}$ курсу по паритету покупательной способности и высокая волатильность валютного курса негативно влияют на инвестиционные и инновационные процессы, препятствуют модернизации производства и импорту передовых технологий и оборудования.

2. Жесткие финансовые ограничения, в последние годы накладываемые федеральными органами власти, сильно сужают пространство бюджетного маневра и сокращают возможности регионального бюджета финансировать инновационные программы и проекты.

3. Правила контроля расходования бюджетных средств плохо приспособлены к специфике инновационного бизнеса. Вложения в инновации, особенно на первых этапах инновационного роста, связаны с большими рисками. Как правило, из 10 стартапов только один становится прибыльным и успешным. Тогда, государственные расходы (субсидии, инвестиции) на другие стартапы могут быть признаны неэффективным расходованием бюджетных средств, что может привести к уголовной ответственности принявшего решение об инвестициях должностного лица [6]. Это крайне негативно сказывается на принятии решений о государственной поддержке инноваций.

4. Крупнейшие государственные и частные холдинги ориентируются на получение сверхприбылей от своего монопольного положения на рынке и тесных связей с государством. Внедрение инноваций и приобретение инновационных технологий и стартапов для них - дело второстепенное.

5. Крупный и средний бизнес не проявляют достаточной инновационной активности, у них нет стимулов к внедрению инноваций. Значительная часть бизнеса опасается связываться с государством и даже избегает получения государственных субсидий из-за сверхжесткого контроля за эффективностью их использования.

6. Система региональной поддержки малого инновационного бизнеса не приводит к успеху, поскольку владельцы стартапа чаще всего получают прибыль только при продаже части бизнеса или выходе на IPO. Оба эти варианта для отечественных малых инновационных предприятий практически труднодоступны, так как фондовый рынок инноваций развит слабо, а крупный российский бизнес не заинтересован в приобретении технологических стартапов.

7. Внедрение инновационных, в частности, цифровых технологий в практику государственного управления требует изменения моделей и правил принятия решений. Значительная часть должностных лиц не склонна к реформированию своей деятельности и, тем более, к сокращению аппарата сотрудников.

Указы Президента России «О национальных целях и стратегических задачах развития Российской Федерации на период до 2024 года» от 7 мая 2018 года [6] и «О национальных целях развития Российской Федерации на период до 2030 года» от 21 июля 2020 года [7] поставили в сфере инновационной деятельности следующие национальные цели:

- ускорение технологического развития Российской Федерации, увеличение количества организаций, осуществляющих технологические инновации, до 50 процентов от их общего числа;

- обеспечение ускоренного внедрения цифровых технологий в экономике и социальной сфере;

- создание в базовых отраслях экономики, прежде всего, в обрабатывающей промышленности и агропромышленном комплексе высокопроизводительного экспортно ориентированного сектора, развивающегося на основе современных технологий и обеспеченного высококвалифицированными кадрами.

Из указанных национальных целей следует, что на современном этапе основной целевой установкой в инновационной сфере является обеспечение внедрения инноваций в экономике, социальной сфере и государственном управлении страны и регионов.

Для выполнения поставленной цели необходимо решить следующие задачи:

- сформировать институциональное и организационное обеспечение внедрения инноваций;

- обеспечить рост инновационной активности крупного и среднего бизнеса и внедрение технологических инноваций;

- создать условия для развития региональных инновационных компаний на этапе роста и привлечения в регион иностранных и отече- 
ственных инновационных компаний с уже апробированными технологическими инновациями;

- поддержка инновационных проектов на этапе стартап и посевной стадии путем их продвижения в федеральных институтах развития, организации бизнес-акселераторов и приобретения акций и долей стартапов;

- осуществлять поиск новых направлений смарт-специализации региона [8] и стимулировать проведение НИОКР по выбранным направлениям с целью создания моделей новых бизнесов, в том числе по NBIC-технологиям (нанотехнологиям, биогенетическим, информационным и когнитивным технологиям);

- совершенствовать информационное обеспечение инновационных процессов на всех этапах развития и распространить инновационную культуру в обществе, бизнесе и государстве.

Предложения по направлениям инновационного развития региона

Исходя из названных проблем, целей и задач можно предложить следующие направления инновационного развития региона.

1. Институциональное и организационное обеспечение инновационного развития. Выполнение трех национальных целей в инновационной сфере требует организации работ во всех отраслях экономики и социальной сферы. С другой стороны, практически все национальные проекты содержат значительные инновационные составляющие. Так, одной из задач национального проекта «Здравоохранение» является «внедрение инновационных медицинских технологий, включая систему ранней диагностики и дистанционный мониторинг состояния здоровья пациентов». Национальный проект «Образование» ставит задачу «создания современной и безопасной цифровой образовательной среды, обеспечивающей высокое качество и доступность образования всех видов и уровней». Национальный проект «Жилье и городская среда» - «модернизация строительной отрасли и повышение качества индустриального жилищного строительства, в том числе посредством установления ограничений на использование устаревших технологий и стимулирования внедрения передовых технологий в проектировании и строительстве, совершенствование механизмов государственной поддержки строительства стандартного жилья». Национальный проект «Экология» - «повышение качества питьевой воды посредством модернизации систем водоснабжения с использованием перспективных технологий водоподготовки, включая технологии, разработанные организациями оборонно-промышленного комплекса». Национальный проект «Безопасные и качественные дороги» - «внедрение автоматизированных и роботизированных технологий организации дорожного движения и контроля за соблюдением правил дорожного движения». Национальный проект «Поддержка малого и среднего бизнеса» - «создание цифровой платформы, ориентированной на поддержку производственной и сбытовой деятельности субъектов малого и среднего предпринимательства, включая индивидуальных предпринимателей».

Наконец, национальные проекты «Повышение производительности труда», «Наука» и «Цифровые технологии» являются многоотраслевыми и посвящены, главным образом, переходу к инновационному развитию.

Таким образом, инновациионная составляющзая присуща практически всем национальным и, следовательно, региональным проектам. От качества выполнения задач этих проектов в сфере инноваций в решающей степени зависит выполнение национальных и региональных проектов. При этом инновационное развитие в различных отраслях проходит по единым экономическим законам, и для управления этими процессами необходимо использовать отработанные методы инновационного менеджмента $[9,10]$. Отсюда следует необходимость координации инновационной деятельности в различных отраслях и региональных проектах.

Для целей координации под руководством первого заместителя губернатора рекомендуется создать Координационный совет по инновациям. В него входят первые заместители осуществляющих региональные проекты департаментов, которые несут персональную ответственность за инновационные составляющие соответствующих региональных проектов и отраслей экономики и социальной сферы.

Основным инструментом координации является Координационный план, охватывающий практически все отрасли и региональные проекты. В каждом Департаменте и/или проектном офисе формируется Рабочая группа по инновациям под руководством первого заместителя Департамента. Регламентируется отчетность выполнения координационного плана, основное внимание в которой уделяется выполнению на- 
циональных и соответствующих региональных задач в сфере инновационной деятельности.

2. обеспечение внедрения технологических инноваций и роста инновационной активности бизнеса и социальной сферы. Выполнение национальной цели «ускорение технологического развития Российской Федерации, увеличение количества организаций, осуществляющих технологические инновации, до 50 процентов от их общего числа» требует увеличения инновационной активности организаций, которая включает не только технологические, но и маркетинговые, организационные и другие инновации.

Статистическое измерение инновационной активности ведется в России Росстатом на основе Четвертого издания «Руководство Осло - Рекомендации по сбору и анализу данных по инновациям» (далее Руководство или «Осло-4») [11], которое является основным методологическим документом Организации экономического сотрудничества и развития (ОЭСР) в области инноваций.

Руководство использует условие «новое для предприятия» в качестве минимального требования к инновации. То есть «инновация - новый или улучшенный продукт или процесс (или их сочетание), которые в значительной мере отличаются от используемых ранее этим предприятием продуктов или процессов и которые доступны потребителям на рынке (для продукта) или используются предприятием (для процесса)».

Продуктовая инновация - новый или улучшенный уже выведенный на рынок товар или услуга, который в значительной мере отличается от используемых ранее этой организацией товаров и услуг.

Процессная инновация - новый или улучшенный процесс, используемый организацией для выполнения одной или нескольких своих функций, который в настоящее время уже используется организацией и в значительной мере отличается от используемых ранее этой организацией бизнес процессов.

Заметим, что согласно предыдущей третьей редакции Руководства «Осло-3» [12], рассматриваются четыре типа инноваций: продуктовые, процессные, организационные и маркетинговые. Продуктовые инновации подразумевают значительные изменения в свойствах производимых товаров и услуг. Процессные инновации - значительные изменения в методах производства и доставки. Организационные инновации - изменения в деловой практике, в организации рабочих мест или во внешних связях предприятия. Маркетинговые инновации - изменения в дизайне и упаковке продукта, в его продвижении и размещении, в методах установления цен на товары и услуги.

В четвертой редакции «Осло-4» маркетинговые и организационные инновации включены в процессные. Технологические инновации объединяют продуктовые и процессные инновации (ТПП).

Инновация оценивается по отношению к продуктам и процессам конкретной организации. Понятия «новое для рынка» и «новое для всего мира» определяют, была ли инновация уже внедрена на других предприятиях или внедрившее ее предприятие оказалось первым на рынке либо в своей отрасли, либо даже во всем мире. Для целей регионального инновационного развития выделяются инновации, новые для региональных рынков. Они называются региональными инновациями.

Инновационной организацией является организация, которая внедрила какую-либо инновацию за период времени, установленный при обследовании. Статистика определяет инновационность организации по затратам на инновации и по результатам инновационной деятельности, которая находит отражения в объектах интеллектуальной собственности.

Исходя из вышесказанного, для стимулирования инновационной активности и роста числа организаций, осуществляющих технологические инновации, необходимы:

- организация правильного учета всех затрат на инновации;

- консультационная поддержка регистрации предприятиями объектов интеллектуальной собственности;

- стимулирование внедрения апробированных в других организациях инновационных технологий.

Организация учета затрат очень важна, поскольку именно по результатам статистического наблюдения определяется инновационная активность, и учет затрат обычно довольно сложен. Для обучения персонала правильному отражению в форме-4 «Инновации» затрат целесообразно проведение семинаров и вебинаров, консультационная работа непосредственно в организациях.

Для консультационной поддержки органи- 
заций при регистрации интеллектуальной собственности целесообразно создание в регионе Центра компетенции по оформлению прав интеллектуальной собственности, а также Центра поддержки технологий и инноваций (ЦПТИ) первого уровня. В перспективе целесообразно создание в регионе сети Центров поддержки технологий и инноваций второго и третьего уровней.

Стимулирование внедрения апробированных инновационных технологий целесообразно вести по отраслям. Для этого организации, включенные в статистическое наблюдение по инновациям и инновационной активности, разбиваются на группы по отраслевому признаку. C каждой отраслевой группой взаимодействует соответствующая данной отрасли Рабочая группа определенного департамента. В каждой группе выделяются организации-лидеры, которые уже являются инновационно-активными. Силами Рабочей группы, и, возможно, привлеченных по конкурсу консалтинговых компаний организации-лидеры исследуются на предмет удачно используемых ими процессных и продуктовых инноваций. Эти инновационные технологии дополняются универсальными инновационными технологиями, подходящими для всех отраслей (например, многие ИТ-технологии). Формируется банк передовых технологий с отраслевым делением.

Организациям каждой отрасли предлагаются к внедрению соответствующие технологии из банка передовых технологий. Технологии могут быть получены путем приобретения патента или лицензии на изобретение, полезную модель или ноу-хау. После надлежащего приобретения и оформления новой технологической инновации внедрившая ее организация становится инновационно активной.

Работу по стимулированию инновационной активности крупных и средних предприятий необходимо вести в координации с работами по проекту «Производительность труда и поддержка занятости». На первом этапе этот национальный (и региональный) проект сфокусирован на внедрении методов бережливого производства, а на втором этапе предполагает модернизацию. Вовлеченные в этот проект организации могут стать опорными для внедрения технологических инноваций.

3. Поддержка региональных инновационных компаний на этапе роста и привлечение в регион иностранных и отечественных инновационных компаний с уже апробированными технологическими инновациями. Почти в каждом регионе уже имеются десятки инновационно-активных предприятий, внедривших перспективные технологии. Значительное число предприятий уже получили гранты на развитие инновационных технологий.

Организации на стадии инновационного развития и роста чаще всего нуждаются в продвижении своей продукции и услуг на новые рынки, в том числе зарубежные. Соответствующие отрасли каждой такой организации Рабочие группы должны оказывать этим организациям поддержку в продвижении на новые рынки и необходимым для этого расширении и модернизации производства:

- для продвижения на рынки других регионов проводятся, приобретаются или заказываются обзоры наиболее перспективных федеральных и региональных рынков, устанавливаются деловые связи с институтами развития, интересными для продвижения продукции конкретных предприятий регионами;

- для продвижения на зарубежные рынки устанавливаются деловые связи с АО «Российский экспортный центр» (РЭЦ), который оказывает финансовую (страховую, кредитную, гарантийную и иную) и нефинансовую (поиск партнеров, акселератор для экспортеров, инвестиционное консультирование в рамках поддержки экспорта и др.) поддержку экспорта;

- для расширения и модернизации производства используются региональный и федеральный фонды развития промышленности, которые предоставляют льготное заёмное софинансирование на проекты, направленные на импортозамещение и производство конкурентоспособной продукции.

Одновременно с этим Координационный совет через Рабочие группы организует работы по обратному процессу - привлечению в регион иностранных и отечественных инновационных компаний с уже апробированными технологическими инновациями.

Поиск таких компаний осуществляется по следующим направлениям:

- компании-резиденты фонда «Сколково», грантополучатели фонда содействия инновациям, фондов «Российской венчурной компании», Роснано, Агентства стратегических инициатив, других федеральных институтов развития, находящиеся на стадии роста и развития и ищущие 
новые рынки сбыта;

- компании, получившие поддержку региональных инновационных систем и перешедшие к этапу развития и роста;

- крупные российские корпорации и инновационные центры, ответственные за развитие сквозных инновационных технологий (Росатом, ПАО «Сбербанк», Курчатовский центр и др.);

- иностранные компании, имеющие испытанные инновационные технологии и желающие войти на российский и, в частности, региональный рынок.

Каждый перспективный проект и предлагающая его компания проходят экспертизу и рассматриваются на отраслевых Рабочих группах. Крупные проекты выносятся на Координационный совет. Рабочие группы и Координационный совет принимают решение о поддержке конкретного проекта на территории региона. Чаще всего для поддержки инновационных проектов необходимо открытие или создание определенного рынка. Многие проекты в сферах экологии, здравоохранения, образования могут быть поддержаны государственными и муниципальными заказами, которые инициируются соответствующими департаментами и предоставляются на конкурсной основе.

4. Поддержка инновационных проектов на этапе стартап и посевной стадии путем их продвижения в федеральных институтах развития, организации бизнесакселераторов и приобретения акций и долей стартапов. Поддержка инновационных проектов на ранних этапах их развития (посевная стадия и стартап) путем предоставления им грантов из бюджета региона во многих регионах не продемонстрировали высокой эффективности. Это обусловлено тем, что на региональном уровне весьма трудно организовать качественную экспертизу проектов.

В связи с этим для таких регионов целесообразно перенести центр тяжести поддержки инновационных проектов с прямого субсидирования за счет бюджетных средств на продвижение этих проектов в федеральных институтах развития, в которых экспертиза поставлена на достаточно высоком уровне.

Национальная инновационная система включает около 50 федеральных институтов развития и различных фондов стимулирования инновационной деятельности. Среди них: Фонд развития и коммерциализации новых техноло- гий (Сколково). Инвестиционный фонд Российской Федерации, Государственная корпорация «Банк развития и внешнеэкономической деятельности (Внешэкономбанк)», ОАО «Российская венчурная компания» (учредитель 22 фондов), Государственная корпорация «Российская корпорация нанотехнологий», ОАО «Российский сельскохозяйственный банк», ОАО «Российский фонд информационно-коммуникационных технологий», Фонд содействия развитию малых форм предприятий в научно-технической сфере, Фонд развития Интернет инициатив и др. [13].

Большая часть этих институтов работает в сфере стимулирования инновационной деятельности. Институты развития имеют свои программы поддержки инноваций, по которым инновационные компании могут получить гранты и другие формы поддержки. Каждая программа и каждый фонд имеют свои правила оформления заявок и требования к претендентам на получение государственной поддержки. Правильно составить заявку и удовлетворить требованиям бывает весьма трудно даже для опытных инновационных компаний. В связи с этим целесообразно создание Центра компетенции по мерам федеральной поддержки стартапов и инновациионных компаний на посевной стадии.

Важным новым направлением поддержки стартапов и посевных компаний становятся бизнес-акселераторы. Зарубежный опыт доказал их эффективность. Так, через бизнесакселератор Y Combinator прошли Airbnb (капитализация 35 млрд. долл.), Stripe (35 млрд. долл.), Dropbox (10 млрд. долл.), Coinbase (1,6 млрд. долл.) и другие (оценка стоимости всех стартапов этого акселератора превышает 100 млрд. долл.) [14].

Бизнес-акселераторы обычно организуются в крупных корпорациях, заинтересованных в развитии инноваций. Они отбирают стартапы или инновационные компании на посевной стадии и обеспечивают быстрое созревание отобранных компаний путем их обучения, использования менторов, включения компаний в деятельность заинтересованных корпораций, отработку наиболее перспективных бизнесмоделей. Иногда отобранные команды обеспечиваются «посевным» финансированием.

Стартап должен быть нацелен на продажу части или всех своих акций (долей участия) или на привлечении финансирования через публичное размещения акций на рынке (IPO). Одной из 
проблем российского инновационного бизнеса является относительно слабое развитие рынка стартапов. У нас, в отличие от США, очень мало инновационных гигантов типа Google, Apple, Microsoft, Facebook, занимающихся массовым приобретением стартапов. В настоящее время руководство страны пытается побудить российские крупные государственные компании (Ростех, Росатом, Роскосмос, Роснефть, Газпром и др.) начать работы с профильными стартапами [15].

Важным направлением поддержки стартапов становится привлечение инвесторов к приобретению их акций (долей участия). Для этого целесообразно использовать:

- организацию взаимодействия владельцев стартапов с представителями федеральных и региональных компаний, которые могут стать инвесторами;

- создание Цифровой платформы инноваций, представляющей собой маркетплейс, где владельцы стартапов предлагают свои компании для приобретения, а инвесторы и бизнесангелы приобретают доли стартапов;

- создание краудфандинг (Crowd-funding) платформы для привлечения частных инвестиций.

С 1 января 2020 года вступил в силу Федеральный закон от 02.08.2019 № 259-ФЗ «О привлечении инвестиций с использованием инвестиционных платформ и о внесении изменений в отдельные законодательные акты Российской Федерации». Этот закон открывает новые возможности привлечения инвестиций в инновационные проекты через краудфандинг и краудинвестинг, создавая для них четкие правовые основания.

5. Поиск новых направлений смартспециализации региона и проведение НИОКР по выбранным направлениям. Для успешного развития региона необходимо не только укреплять его конкурентные позиции в традиционных отраслях, но и постоянно искать новые направления смарт-специализации («умной» специализации), которая представляет собой набор правил по выбору приоритетов в рамках стратегии инновационного развития. Эти правила собраны в едином методическом документе ЕС - «Руководстве по разработке исследовательских и инновационных стратегий смарт специализации» (Guide to Research and Innovation Strategies for Smart Specializations)
[16].

Смарт-специализация должна быть перспективной с позиций инновационного развития и использовать традиционные конкурентные преимущества региона. Исходя из современных тенденций инновационного развития наиболее многообещающими являются NBIC-технологии (нано-, биогенетические, информационные и когнитивные технологии).

Для развития новых направлений смартспециализации, включая NBIC-технологии, необходимо выявить в каждой специализации наиболее перспективные с позиций уже имеющихся достижений и прогнозов научнотехнологического прогресса темы и привлечь к ним ученых, инноваторов и бизнес.

Для этой цели лучше всего подходит апробированный в развитых странах (США, Германия и др.) подход, основанный на проведении по перспективной тематике специальных НИОКР. На базе опроса экспертов в определенном направлении смарт-специализации выбирается перспективная тематика. Эти тематики полезно обсудить на конференциях и форумах с участием ведущих в мире специалистов.

В ходе проведения НИОКР выбранный по конкурсу исполнитель исследует достижения по этой теме в развитых странах, выбирает и описывает наиболее перспективные инновационные бизнесы, уже продемонстрировавшие свою эффективность в зарубежных странах или в других регионах нашей страны и обосновывает бизнес-модель, которая предлагается для внедрения региональному инновационному бизнесу. При этом эффективность предлагаемой бизнес-модели желательно продемонстрировать на пилотном объекте.

Проведение НИОКР и создание пилотной бизнес-модели является важнейшим элементом стимулирования освоения новых направлений смарт-специализации.

6. Совершенствование информационного обеспечения инновационных процессов и распространение инновационной культуры в обществе, бизнесе и государстве. Информационное обеспечение является, с одной стороны, важной составляющей инноваций и, в другой стороны, необходимым элементом инновационной инфраструктуры.

Специального информационного обеспечения требует работа Координационного совета и Рабочих групп по инновациям в департаментах. 
Отдельные сайты или разделы должны быть посвящены мониторингу работ по стимулированию инновационной активности организаций по отраслям. Важным программным комплексом, входящим в информационное обеспечение инновационной деятельности, может стать Цифровая платформа инноваций. На этом маркетплейсе владельцы стартапов предлагают свои компании для приобретения, а инвесторы и бизнес-ангелы приобретают доли стартапов. Цифровая платформа инноваций будет программно связана с платформой краудфандинга и краудинвестиций.

Цифровые коммуникации, включая пропаганду инновационной культуры через средства массовой информации и Интернет, Интернеттелевидение, создание специализированных телевизионных передач, являются важнейшими, но не единственными каналами распространения инновационной культуры. Для повышения инновационной культуры также могут служить: проведение выставок, конкурсов, в том числе интерактивных, конференций и форумов по инновационной тематике.

Критерии эффективности инновационной политики

Главными критериями оценки эффективности являются уровень инновационной активности организаций региона и доля организаций, осуществляющих технологические инновации. Критериями оценки эффективности работ по отдельным направлениям могут выступать:

- дополнительная выручка, которую принесло внедрение инновационных проектов предприятий данного региона в других регионах и странах;

- дополнительная выручка, которую принесло внедрение в регионе инновационных проектов предприятий, расположенных за ее пределами;

- число зарегистрированных объектов интеллектуальной собственности организаций региона (патенты, полезные модели, промышленные образцы), а также общая сумма денежных средств, полученная от их использования (лицензии, переуступка прав на объекты интеллектуальной собственности).

Качественные оценки развития инновационной инфраструктуры, информационного обеспечения инноваций и роста инновационной культуры могут быть получены на основе социологических опросов населения и бизнеса.
Оценка различных аспектов инновационной деятельности относительно достигнутых другими регионами результатов может проводиться по авторитетным рейтингам и индексам, таким как рейтинг по индексу социально-экономических условий инновационной деятельности (ИСЭУ), рейтинг субъектов по индексу инновационной деятельности (ИИД), рейтинг субъектов по индексу качества инновационной политики (ИКИП) и другим.

\section{Заключение}

Стратегия инновационного развития региона является одним из документов, определяющих его стратегическое развитие и конкретизирующих Стратегию социально-экономического развития региона в сфере инновационной деятельности. Инновационная деятельность носит межотраслевой характер и, наряду с отраслевой спецификой, она характеризуется общими закономерностями инновационного развития, в связи с чем, для управления ей необходимы единая многоотраслевая программа и координация действий.

Региональная инновационная система может обеспечить определенную поддержку инновационной деятельности, но не приводит к широкому внедрению инноваций в бизнесе и социальной сфере, поэтому на современном этапе необходима специальная программа внедрения инноваций и стимулирования роста инновационной активности предприятий. Национальная инновационная система, федеральные институты развития, холдинги и крупные компании уже создали, провели качественную экспертизу, испытали в реальных условиях и подготовили к широкому масштабированию достаточно много технологических инноваций, для использования которых на предприятиях региона необходимо создать для этих инноваций рынки сбыта и благоприятные условия работы.

В Стратегии инновационного развития Российской Федерации на период до 2020 года в качестве оптимального предлагается «вариант развития с элементами лидерства в некоторых сегментах экономики, в которых имеются (или могут быть быстро созданы) конкурентные преимущества, но с реализацией догоняющего варианта в большинстве секторов экономики». Следовательно, значительные усилия следует направить на различные формы заимствования иностранных инновационных технологий.

Финансовая поддержка стартапов на регио- 
нальном уровне оказывается недостаточно эффективной из-за невысокого уровня экспертизы проектов и весьма ограниченных финансовых ассигнований на гранты и субсидии по этому направлению; в связи с этим на современном этапе целесообразно направить основные усилия на консультационную поддержку и продвижение региональных стартапов на федеральном уровне.

Для поддержки инноваций на стадии НИИОКР (seed, посевная стадия) целесообразно инициировать проведение НИИОКР в перспективных с позиций смарт-специализации региона сферах, особенно в областях генетических и цифровых технологий, а также других NBIC-технологий.

\section{Библиографический список}

1. Голиченко О.Г.Государственная политика и провалы национальной инновационной системы. https:/ institutiones.com/innovations/2960-gosudarstvennaya-politika-provaly-nacionalnoi-innovacionnoi-sistemy. html (c) Экономический портал

2. Manufacturing USA. https://www.manufacturingusa.com/

3. Bloomberg оценил возможный ущерб от эскалации торговой войны США и Китая. https://www.forbes.ru/ biznes/378683-bloomberg-ocenil-vozmozhnyy-ushcherb-ot-eskalacii-torgovoy-voyny-ssha-i-kitaya

4. Каблов Е.Н. Шестой технологический уклад. https://www.nkj.ru/archive/articles/17800/

5. Чубайс А.Б. О провале инновационной стратегии, конкуренции в политике и угрозе тюрьмы. https://www. znak.com/2018-07-10/chubays_o_provale_innovacionnoy_strategii_konkurencii_v_politike_i_ugroze_tyurmy

6. Указ Президента Российской Федерации от 07.05.2018 г. № 204 О национальных целях и стратегических задачах развития Российской Федерации на период до 2024 года. http://kremlin.ru/acts/bank/43027

7. Указ Президента Российской Федерации от 21.08.2020 г. О национальных целях развития Российской Федерации на период до 2030 года. http://kremlin.ru/events/president/news/63728

8. Бош А. Вонартас Н. «Умная специализация» как стимул инновационной экономики в развивающихся странах. Уроки Бразилии. ФОРСАЙТ Т. 13 № 12019.

9. Кристенсен К.М., Скотm Э., Рот Э. Что дальше? Теория инноваций как инструмент предсказания отраслевых изменений / - 3-е изд. - М.: Альпина Пабл., 2016._400 c. http://znanium.com/catalog/product/561220

10. Piperopoulos P. Entrepreneurship, Innovation, and Business Clusters. - Abingdon: Routledge, 2016.

11. OECD/Eurostat (2018), Oslo Manual 2018: Guidelines for Collecting, Reporting and Using Data on Innovation, 4th Edition, The Measurement of Scientific, Technological and Innovation Activities, OECD Publishing, Paris/Eurostat, Luxembourg. https://doi.org/10.1787/9789264304604-en

12. Руководство Осло рекомендации по сбору и анализу данных по инновациям. Третье издание. Совместная публикация ОЭСР и Евростата. 2006. http://rii-vuz.extech.ru/doc/oslo.pdf

13. http://innovation.gov.ru/taxonomy/term/543

14. https://www.ycombinator.com/

15. Путин призвал «Ростех», «Роскосмос» и «Росатом» работать со стартапами. https://tsargrad.tv/news/putinprizval-rosteh-roskomos-i-rosatom-rabotat-so-startapami_66825

16. Guide to Research and Innovation Strategies for Smart Specializations (RIS 3). Luxembourg: Publications Office of the European Union, 2012.https://ec.europa.eu/regional_policy/sources/docgener/presenta/smart_specialisation/ smart_ris3_2012.pdf 